\title{
LAS ACUÑACIONES HISPANORROMANAS Y SU INFLUENCIA EN LAS IMÁGENES DE CASTILLOS Y MURALLAS EN LA HERÁLDICA HISPÁNICA
}

\author{
Alberto Aguilera Hernández*
}

\begin{abstract}
Resumen: A lo largo de los siglos XVI y XVII numerosas localidades experimentaron procesos de redefinición identitaria favorecidos por condicionantes políticos, religiosos, culturales, sociales y económicos muy concretos que se visibilizaron en la renovación total o parcial de sus escudos de armas concejiles. En el presente estudio analizamos la desigual proyección institucional que tuvieron las fortificaciones como muebles heráldicos en estos contextos y la influencia que en la misma tuvieron las imágenes que figuran en las acuñaciones cívicas hispanarromanas, un repertorio iconográfico clave en la conformación de las nuevas identidades cívicas.
\end{abstract}

Palabras clave: numismática, heráldica, corografía, hagiografía, identidad cívica, Edad Moderna.

Hispano-Roman coinage and its influence on the images of castles and walls in Hispanic heraldry

Abstract: During the 16th and 17th centuries numerous localities underwent processes of identity redefinition favoured by very specific political, religious, cultural, social and economic conditionaing factors manifested in the total or partial renewal of the heraldic arms of their Councils. In this paper we study the unequal institutional projection of fortifications as heraldic elements in these contexts, and the influence on them of images appearing on Hispano-Roman civic coinages, a key iconographic repertory in the creation of the new civic identities.

Key words: numismatics, heraldry, corography, hagiography, civic identity, Modern Age.

\section{INTRODUCCIÓN}

En 1535 la ciudad de Nimes alcanzó del rey Francisco I de Francia la autorización para asumir como emblema cívico concejil la imagen de un cocodrilo atado a una palmera flanqueado por la mención toponomástica COL - NEM (fig. 1), que vino a sustituir al toro de oro pasante que el mismo monarca permitió usar en 1516 (Durand, 1962; Sauzet, 1998, 49-61). La composición, que

Data de recepció: 15 d'abril de 2020 / Data d'acceptació: 3 d'agost de 2020.

* Doctor en Historia por la Universidad de Zaragoza. Centro de Estudios Borjanos de la Institución "Fernando el Católico". 
hoy en día se encuentra omnipresente en numerosos espacios urbanos de la localidad, es el tipo iconográfico característico de los reversos de las acuñaciones ${ }^{1}$ que su antecesora romana, la Colonia Augusta Nemausus (fig. 2), batió

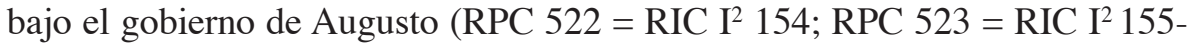
157; RPC $524=$ RIC I 158 y RPC $525=$ RIC I I $\left.^{2} 159-161\right)$. Estas emisiones tuvieron una clara intencionalidad propagandística debido a la marcada carga identitaria del emblema, que refiere el asentamiento de veteranos legionarios que contribuyeron a derrotar a Marco Antonio y Cleopatra en la batalla naval de Actium del 31 a.C. y a la conquista de Egipto del año siguiente (Veyrac, 1998; Suspène, 2012, 23-34; Puech, Puech, Puech, 2014, 58-66; Amela, 2017, 51).

En líneas generales, podemos decir que la modificación del blasón se produjo en el marco de la importancia que el Renacimiento otorgó a las monedas de la Antigüedad como objetos coleccionables por su belleza y valor pedagógico, como piezas fundamentales para el conocimiento de la Historia y en la transmisión de virtudes, valores y modelos, tanto artísticos como sociales (Maravall, 1966; Egido, 1984, 211-227; Domínguez, 2008, 205-218; Blázquez, 2013, 363376; 2014, 15-36; 2016, 1217-1230). Además, en el contexto local la decisión se encuadró en un ambiente cultural controlado por una élite política humanista interesada en el redescubrimiento del pasado de la ciudad, para lo cual promovió acciones dirigidas a consolidar la leyenda hercúlea de sus orígenes y a revalorizar el patrimonio arquitectónico romano, tal y como encontramos en la conocida obra de Poldo d'Albenas (1560), todo ello para alcanzar y justificar un prestigio superior al de Montpellier, localidad rival creada en el siglo VIII d.C.

$\mathrm{Al}$ igual que Nimes, en la Monarquía Hispánica comprobamos que durante la Edad Moderna numerosas ciudades asistieron a una modificación interesada de sus rasgos definidores identitarios que se reflejó en la sustitución o reforma de los escudos de armas concejiles. Una fórmula más, puesta al servicio de la autorrepresentación simbólica de esta clase dirigente, que también recurrió a la literatura para forjar su nueva conciencia ciudadana.

En efecto, las obras de género corográfico que vamos a citar en este estudio, y que no debe perderse de vista que fueron patrocinadas por las propias institu-

${ }^{1}$ La cara de la moneda no es un elemento de menor importancia en esta materia, ya que autores como Cunnally (1990) defienden que a partir de Petrarca el coleccionismo numismático giró en torno al interés retratístico que ofrecían los anversos, mientras que solo más tarde, aproximadamente desde la primera mitad del siglo XVI, los reversos comenzaron a ser objeto de una mayor atención. Asimismo, en lo que respecta a estas emisiones galas, su clasificación como moneda imperial o provincial dista de estar resuelta, por lo que recomendamos la sintetizada revisión que se ofrece en RPC pp. 152-153 y Besombes (2008, 235-242). 


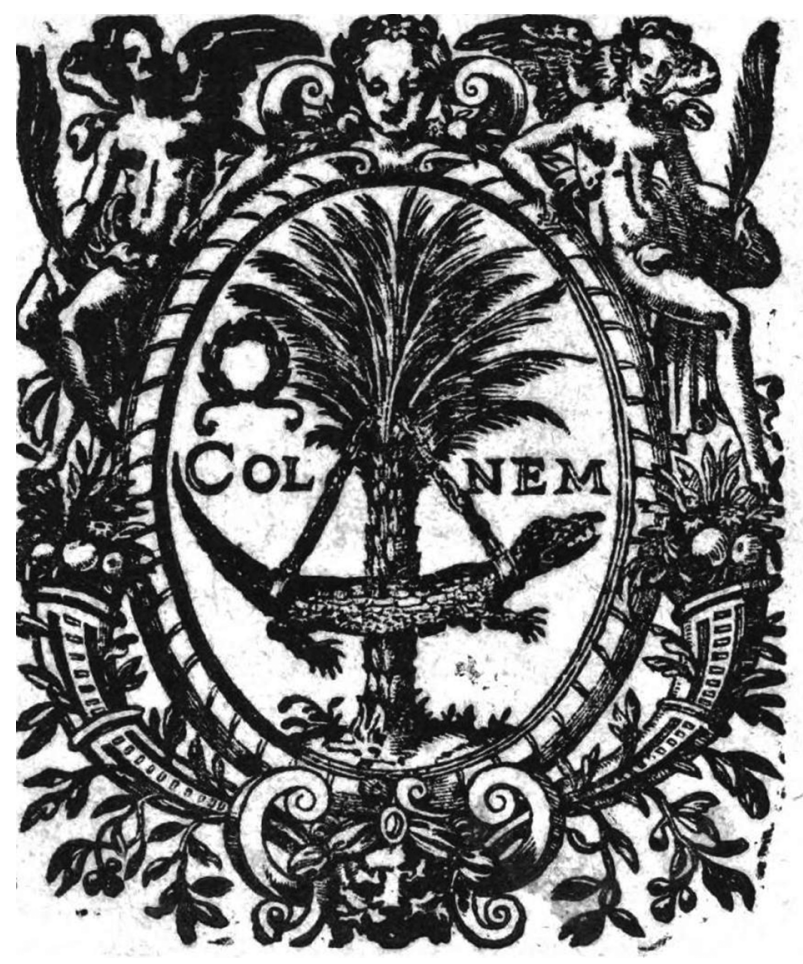

Fig. 1. Escudo de Nimes en la portada de la obra de Jacques Deyron, Des Antiquités de la ville de Nismes de 1663. Ejemplar de la Bibliothèque municipale de Lyon.
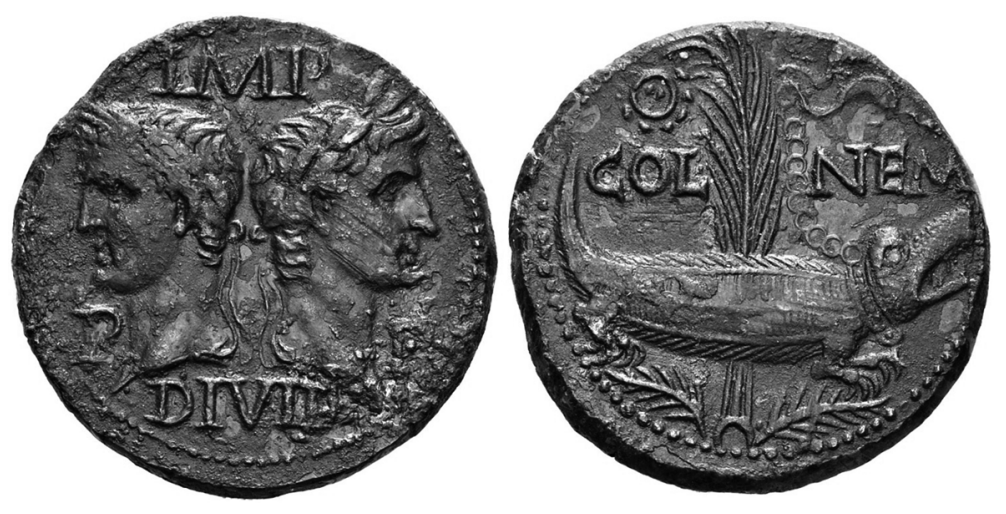

Fig. 2. As (RPC 525) acuñado en la ceca de Colonia Augusta Nemausus con el cocodrilo atado a una palmera como tipo iconográfico del reverso. c. 10-14 d.C. (HessDivo AG, auction 334, lot. 92, 29 May 2018. Foto: www.coinarchive.com). 
ciones concejiles, nacieron dentro de estos mismos parámetros que estamos delimitando y con la misma finalidad: mostrar la reconstrucción mítica de un pasado glorioso sobre el que forjar la identidad local (Wulff, 1993; Kagan, 1995, 47-60; Alvar, 2001, 445-460; Aranda, 2001, 141-168; 2006, 7-48; Jarque, 2013, 171198; Aranda, 2014, 23-62). En buena medida, esta imagen también se construyó a través de la propaganda hagiográfica característica del catolicismo postridentino, es decir: con la potenciación del culto a los santos propios por ser nacidos y/o martirizados en esas comunidades ciudadanas, cuya reivindicación -0 apropiación en determinados casos- ${ }^{2}$, posibilitó honrarlas como patrias de santidad frente a municipios próximos y rivales (Gómez Zorraquino, 2010, 39-74).

Así pues, en el presente estudio hemos querido analizar tres casos hispanos que ilustran los tratamientos diversos de los que fueron objeto las fortificaciones en los escudos de armas municipales -entendiendo como tales a murallas, castillos y torres (Valero de Bernabé, 2007, 511-547)- en el marco de estos procesos de reconstrucción de identidades. Huesca, Mérida (Badajoz) y Elche (Alicante) ofrecen contextos y particularidades locales distintas y, por ello, circunstancias políticas, religiosas, sociales y culturales diferentes que determinaron la eliminación, adopción o redefinición de sus muebles heráldicos en los siglos XVI y $\mathrm{XVII}^{3}$, decisión en la que el conocimiento de las acuñaciones que estas mismas ciudades realizaron en época julio-claudia y la reinterpretación de las que fueron objeto las imágenes grabadas en ellas tuvieron un enorme peso.

\section{HUESCA Y LA ELIMINACIÓN DE LA MURALLA}

Los elementos definidores del escudo medieval de la capital altoaragonesa son herederos directos de los sellos concejiles utilizados en la Baja Edad Media: un lienzo de muralla con una puerta flanqueada por dos torres a cada lado y una muesca de dos puntas sobre campo de gules (fig. 3). Así los encontramos en el ejemplar existente en el patio del ayuntamiento que se fecha hacia 1578, o en el escudo xilográfico que preside la portada del libro Oscensis vetustissimi gymnasii, adversus novam Caesaraugustani attentatam erectionem, iuridica propugnatio, obra apologética de 1585 en defensa de la Universidad

${ }^{2}$ Sobre las falsificaciones del santoral cristiano en los siglos XVI y XVII remitimos a la clásica obra de Godoy (1868).

${ }^{3}$ En líneas generales los emblemas de los antiguos escudos de armas de estas localidades ya habían sido formulados previamente en las improntas de sus sellos concejiles medievales. Sobre el tema véase: Martínez Llorente (2011, 151-166) y Menéndez Pidal (1993, 47-66; 1999, 309-322). 


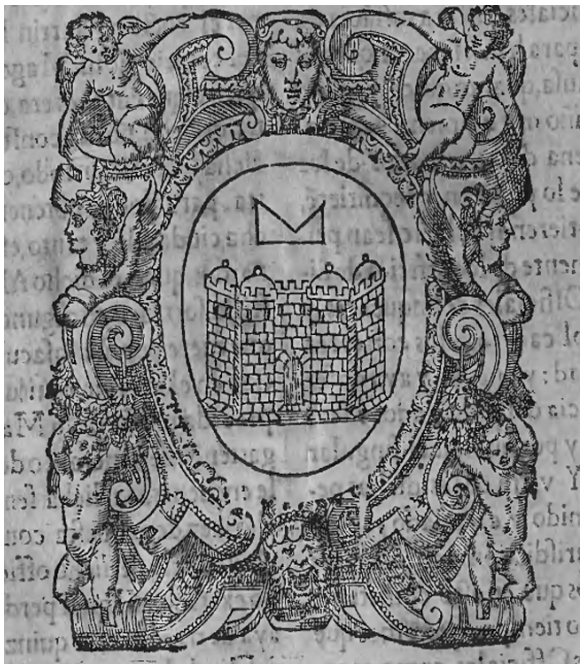

Fig. 3. Escudo medieval de Huesca en las Ordinaciones del Regimiento de 1587. Ejemplar de la Biblioteca de la Universidad de Zaragoza.

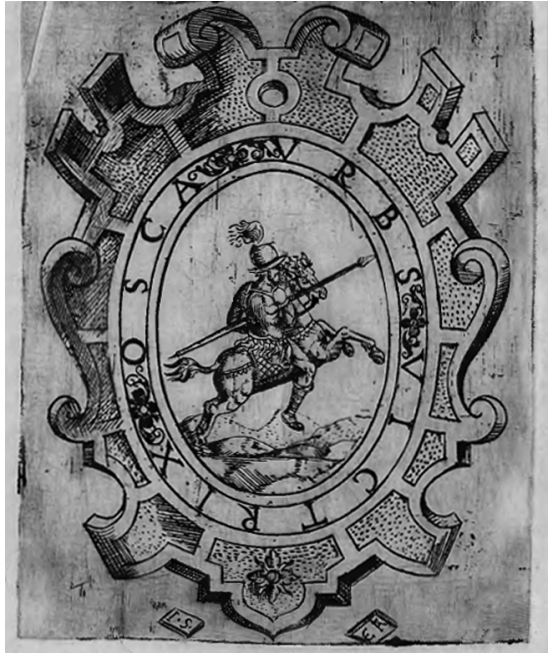

Fig. 4. Nuevo escudo de Huesca en las Ordinaciones del Regimiento de 1587. Ejemplar de la Biblioteca de la Universidad de Zaragoza.
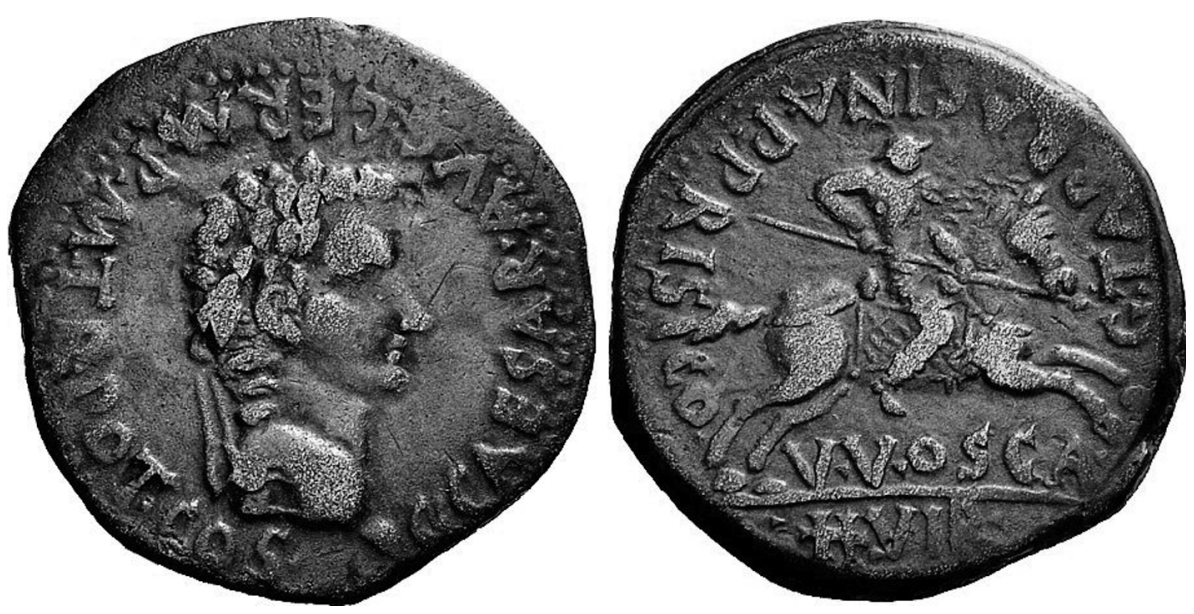

Fig. 5. As (RPC 302) acuñado en Vrbs Victrix Osca con el jinete lancero como tipo iconográfico del reverso. 37-41 d.C. (Jesús Vico SA, auction 132, lot. 630, 14 November 2012. Foto: www. numisbids. com). 
de Huesca frente a la de Zaragoza cuyo autor fue Martín Monter de la Cueva, antiguo rector de la primera de las instituciones universitarias citadas.

Sin embargo, tan solo dos años después la portada de las Ordinaciones del Regimiento (Huesca, 1587) ya contiene un nuevo escudo calcográfico que presenta la imagen de un jinete lancero circundado por el lema VRBS VICTRIX $\mathrm{OSCA}^{4}$ (fig. 4), icono que podemos calificar como el más representativo de la ceca provincial de Osca (fig. 5) (Domínguez Arranz, 1991; Domínguez Arranz y Aguilera, 2014, 92-95; Aguilera, 2016, 79-82), el oppidum ciuium romanorum al que alude Plinio ( $H N 3.24)$, ya que es el que preside el reverso de los dupondios y ases acuñados a nombre de los emperadores Augusto (RPC 281, 283-285, 287 y 289), Tiberio (RPC 291, 295-297) y Calígula (RPC 300 y 302). Asimismo, también los epítetos Vrbs y Victrix, que proclamaban en el topónimo oficial del municipio su condición urbana y su calidad de ciudad victoriosa, tuvieron un amplísimo eco epigráfico en las emisiones de estos tres reinados (Domínguez Arranz, 1991; Aguilera, 2016, 82-90) .

El nuevo blasón oscense, que al parecer obedeció al diseño planteado por el platero Andrés Cetina y por el erudito Jerónimo Bocanegra de Segura, nació y se asumió con una clara intención legitimadora para los intereses de la Universidad de Huesca, seriamente amenazados a raíz de la fundación de la Universidad de Zaragoza en 1583 según hemos adelantado (Garcés, 2002, 245). Así es, la creación de esta última por el prelado Pedro Cerbuna se entendió como una violación del antiguo privilegio de 12 de marzo de 1354 por el que Pedro IV no solo instituyó en la capital altoaragonesa un estudio general para las materias de Teología, Cánones, Letras, Medicina y Filosofía, sino la exclusividad de su impartición en todo el reino a excepción de la de Teología. Por ello, la intensa batalla que ambas ciudades libraron en defensa de sus intereses y derechos se dio en diversos ámbitos e instancias (Garcés, 2002, 246-256; 2006, 38-44; Serrano, 2016, 42-87): ante el propio monarca Felipe II, en las Cortes de Monzón (Huesca) de 1585 y en las de Tarazona (Zaragoza) de 1592, en varios tribunales de justicia y, por supuesto, también en el terreno de la propaganda a través de la recuperación y exaltación de la figura de Quinto Sertorio.

A este respecto, debemos recordar que varios autores clásicos (Strab. 3. 4. 10; Plut. Vit. Sert. 14. 25-26; Vell. Pat. 2. 30; Flor. 2. 10) aluden a Osca como

\footnotetext{
${ }^{4}$ Destacamos que aunque la portada muestra el nuevo escudo el antiguo sigue en vigor cerrando el texto.

${ }^{5}$ Debe tenerse en cuenta que el tipo iconográfico del jinete, característico de los reversos del numerario de las cecas de Hispania Citerior, se encuentra presente en los denarios y unidades batidos por la ceca indígena de bolśkan desde el inicio de su actividad monetaria, a comienzos de la segunda mitad del siglo II a.C. (Domínguez Arranz y Aguilera, 2014).
} 
importante escenario de la crisis romano-republicana en el marco de la guerra que Cneo Pompeyo Magno y Sertorio libraron en Hispania, ya que fue la capital de este último y actuó como un remedo de Roma, albergando un Senado de más de 300 miembros y un collegium iuиenum para los hijos de los nobles hispanos del que nos da noticia Plutarco (Vit. Sert. 14). Precisamente, esta cita fue la que posibilitó que la Universidad de Huesca pudiera retrotraer sus orígenes al siglo I a.C., haciendo al sabino el fundador mítico de la autodenominada desde entonces como "Universidad Sertoriana" frente a la recién creada Universidad de Zaragoza, por lo que no es extraño que el Concejo oscense tomara como propia esta causa en el marco de construcción de una nueva conciencia ciudadana a partir del prestigio que le otorgaba la romanidad.

Ahora bien, dado que la identidad cívica no siempre se mostró estática ni uniforme en el tiempo, tenemos que considerar que la imagen del jinete lancero pudo tener significados polisémicos, paralelos y compatibles si se produjo algún cambio importante en la realidad social que la generó, siempre y cuando fuera posible su redefinición y adecuación a circunstancias distintas. A nuestro juicio, así es como debe interpretarse la petición que el 30 de marzo de 1592 realizó Andrés Cetina al Concejo para que adoptara oficialmente el escudo del jinete, y no solo porque "esta ciudad de Huesca, en el tiempo de los romanos $\mathrm{y}$ antes que huviese emperadores llevava las armas que estan agora estanpadas en las Ordinaciones del Regimiento" (Garcés, 2006, 31-32), sino porque en el mes anterior, más en concreto el 19 de febrero, 300 oscenses habían contribuido a repeler el intento de invasión armada del valle de Tena a manos de bearneses, en su mayor parte protestantes afectos de Antonio Pérez del Hierro (Sanz, 1992, 67-84; 2000, 143-156). De esta forma, como ya apuntó Garcés (2006, 31-32), el jinete comenzó a ser objeto de una lectura paralela, puesto que tanto la iconografía guerrera de la composición como la referencia epigráfica de "ciudad victoriosa" se adecuaban perfectamente al contexto en el que se había producido esta nueva gesta al servicio de la Monarquía.

\section{MÉRIDA Y LA INCORPORACIÓN DE LA MURALLA}

Los escudos conservados en algunas de las iglesias y conventos de Mérida confirman que las primitivas armas del municipio (fig. 6) constaban de un león cobijado por un arco de piedra (Morales-Pogonowski, 2001, 38-45). El animal ya era empleado como tipo principal del sello concejil desde al menos 1406, y lo más seguro es que remita al Reino de León, cuyo titular, Alfonso IX, reconquistó la ciudad en 1230 (Morales-Pogonowski, 2001, 37-38). Por su parte, el 
arco debe identificarse con el conocido como "Arco de Trajano", asumido como icono cívico en el siglo XVI (Moreno de Vargas, 1633, 30-31).

Sin embargo, en los primeros años del Seiscientos se asistió a una renovación total de las armas heráldicas (Morales-Pogonowski, 2001, 48-88) que pasaron a contener como mueble una puerta geminada de la muralla ${ }^{6}$ acompañada por la leyenda AVGVSTA EMERITA (fig. 7). Se trata de uno de los diseños iconográficos más característicos de la moneda imperial (RIC I ${ }^{2}$ 9a, 9b, 10, 11a y 11b) acuñada en la ciudad entre el 25 y el 23 a.C. a nombre del legatus pro praetore Tito Publio Carisio, y también posteriormente, en las series coloniales y provinciales bajo los gobiernos de Augusto (RPC 10 y 12) y Tiberio (RPC 20-27, 30-33, 38, 41- 44) hasta la clausura de la ceca (Álvarez, 1954, 229-243; Cebrián, 2013).

La historiografía tradicional ha insistido en la influencia que pudo ejercer el historiador local Bernabé Moreno de Vargas a la hora de materializarse este cambio pues, además de ostentar el cargo de regidor perpetuo del Concejo, dos de sus obras, Discursos de la nobleza de España e Historia de la ciudad de Merida, publicadas respectivamente en 1622 y 1633, ya justifican el uso de la nueva composición (fig. 8). Sin embargo, y aun reconociendo que ambos trabajos pudieron tener un fuerte impacto en la ciudad, no favorecieron la sustitución del escudo, pues para entonces ya había tenido lugar ${ }^{7}$, sino que en todo caso contribuyeron a su fortalecimiento como emblema cívico identitario, hecho que no excluye que Moreno de Vargas fuera uno de los responsables de su asunción oficial, si bien en un grado que ignoramos por el momento.

Con respecto a las razones que llevaron a tomar esta decisión, opinamos que se justifican en la tradicional rivalidad existente entre Mérida y Badajoz, que además llegaron a compartir el león como mueble heráldico en sus respectivos blasones municipales (Cordero, 2005-2006, 183-228), lo que pudo acelerar la necesidad de diferenciación del Concejo emeritense y la búsqueda de un nuevo diseño que fuera el reflejo de una conciencia cívica completamente renovada. En efecto, la pujante Colonia Augusta Emerita, capital de la provincia romana de Lusitania, dio paso a una decadente ciudad a partir del periodo

${ }^{6}$ En la actualidad todavía no hay unanimidad a la hora de reconocer la puerta representada con ninguna de las identificadas en los últimos años mediante las excavaciones de la muralla. Para algunos correspondería a la conocida como "Puerta de la Villa" y para otros a la "Puerta del Puente" (Hernández, 1998, 34 y ss., Álvarez Martínez, 2006, 221-251).

${ }^{7}$ El mismo Moreno de Vargas $(1622,123)$ informa que "pocos años ha, que con mayor error solamente traian [las armas] el arco, y en el hueco del un león rampante (...) y conociendo el engaño destas armas las ha dexado esta ciudad y buelto a traer las antiguas (...) como lo vemos en muchas monedas suyas". 


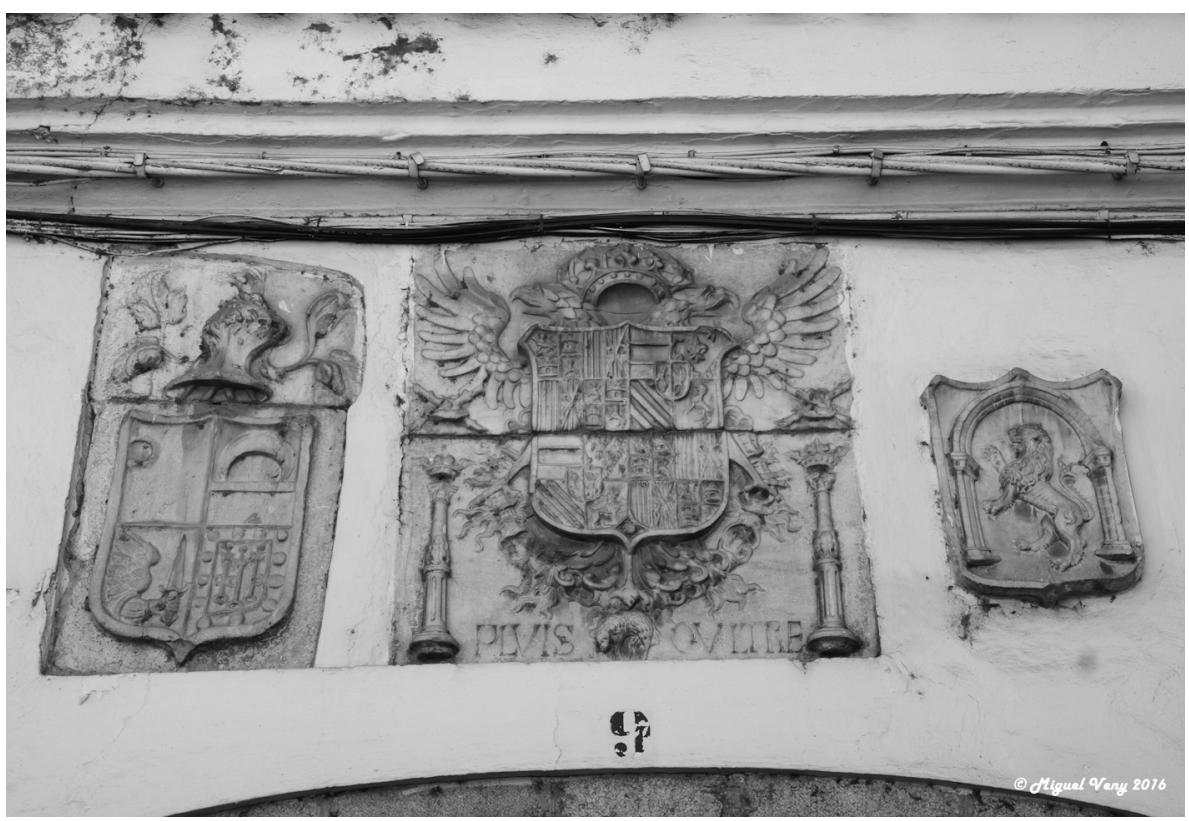

Fig. 6. Escudo imperial de Carlos V flanqueado por el del gobernador Hernán Álvarez de Meneses (izq. del espectador) y el del antiguo Concejo de Mérida (dcha. del espectador). Antigua carnicería del Concejo. 1541 (Fotografía: D. Miguel Veny).
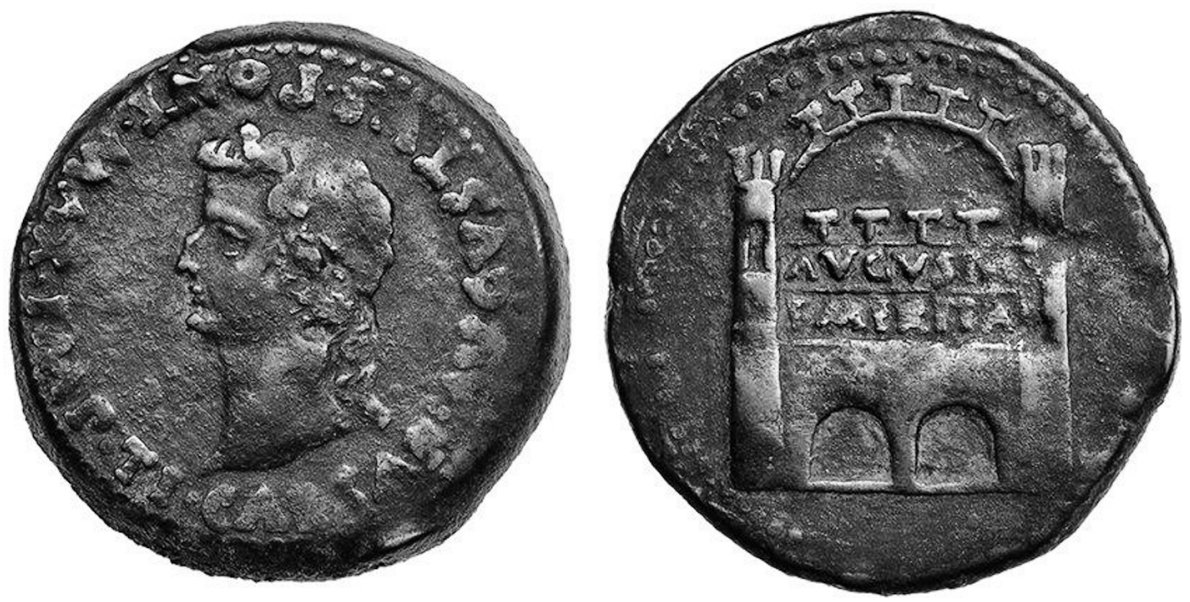

Fig. 7. Dupondio (RPC 41) acuñado en Augusta Emerita con la puerta de la ciudad como tipo de reverso. 14-37 d.C. (Jesus Vico S.A, auction 151, lot. 213, 7 June 2018. Foto: www.coinarchive.com). 
emiral, cuando fue reemplazada por Badajoz en el organigrama político, militar y religioso de la región desde su fundación en el 875 d.C. La reconquista de ambas plazas por Alfonso IX de León en 1230 reforzó esta misma posición jerárquica, de tal modo que Mérida pasó a ser propiedad de la Orden de Santiago (Ballesteros, 2004, 53-66; López, 2009, 143-174) pero Badajoz, que quedó dentro del realengo, fue elevada a cabeza de un obispado en 1255. Por su parte, la silla metropolitana emeritense jamás se restauró ${ }^{8}$, permaneciendo sus derechos temporales en la archidiócesis de Santiago de Compostela desde al menos 1119. Además, tampoco debe pasarse por alto que en el siglo XVII Badajoz se identificaba erróneamente con la colonia Pax Augusta que cita Estrabón (3. 2. 15) ${ }^{9}$, lo que en la práctica le permitía sostener la antigüedad de la diócesis, conectarse con las primitivas comunidades cristianas y defender un origen apostólico a través de la figura del obispo de Braga San Pedro de Rates, discípulo de Santiago el Mayor (Cerrillo, 2009, 42).

A nuestro entender, esta realidad fue clave para que Mérida reaccionara instrumentalizando su pasado y lo visibilizara oficialmente a través del tipo más representativo de sus acuñaciones monetarias romanas, una respuesta en la que el interés "hagiolátrico" focalizado en la figura de Santa Eulalia y sus reliquias, cuyo culto se estaba revitalizando extraordinariamente desde comienzos del siglo XVII según Moreno de Vargas $(1633,174)$, también estuvo muy presente. No en vano, una gran parte de los monumentos o espacios de culto de la santa, conocidos popularmente como "lugares eulalienses", tienen su origen en esta misma época (Barrera, 1993, 125-140; Morales-Pogonowski, 2001, 139-145; Castro, 2012), por lo que no es extraño que cuando Moreno de Vargas $(1622,124)$ describió el nuevo escudo de armas de la ciudad afirmase que "el mayor blason que esta ciudad tiene, es tener por timbre de su escudo, y por su patrona y defensora, a la gloriosa virgen y martyr Santa Eulalia, su natural". De esta aseveración se infiere que la glorificación pública del pasado romano de Mérida a través de la imagen de la puerta de la muralla resultó una acción

${ }^{8}$ De hecho, no fue hasta el 28 de julio de 1994 cuando el papa San Juan Pablo II, a través de la bula Universae Ecclesiae sustinentes, creó la Provincia Eclesiástica de MéridaBadajoz, con lo que la iglesia de Santa María la Mayor de Mérida se convirtió en concatedral.

9 Hoy en día se fija el emplazamiento de esta ciudad en Beja (Portugal). Únicamente Estrabón la denomina Pax Augusta, mientras que Plinio (NH 4. 117) la llama colonia Pacense. En cambio, las restantes fuentes literarias (It. Ant. 427.3, 431.4-5, 431.7; Rav. Cosm. 306.7; Ptol. Geog. 2.5.4), epigráficas (CIL II, 47 y 55) y numismáticas (RPC 52 y 53; RPC $\mathrm{S}-52 \mathrm{~A} / 1)$ recogen el nombre de Pax Iulia, incluso en el caso de CIL II 47 aparece la referencia abreviada a su condición jurídica de colonia. De cualquier forma, Marques de Faria (2001, 351-353) analiza tanto la titulatura como la posible fecha de fundación. 


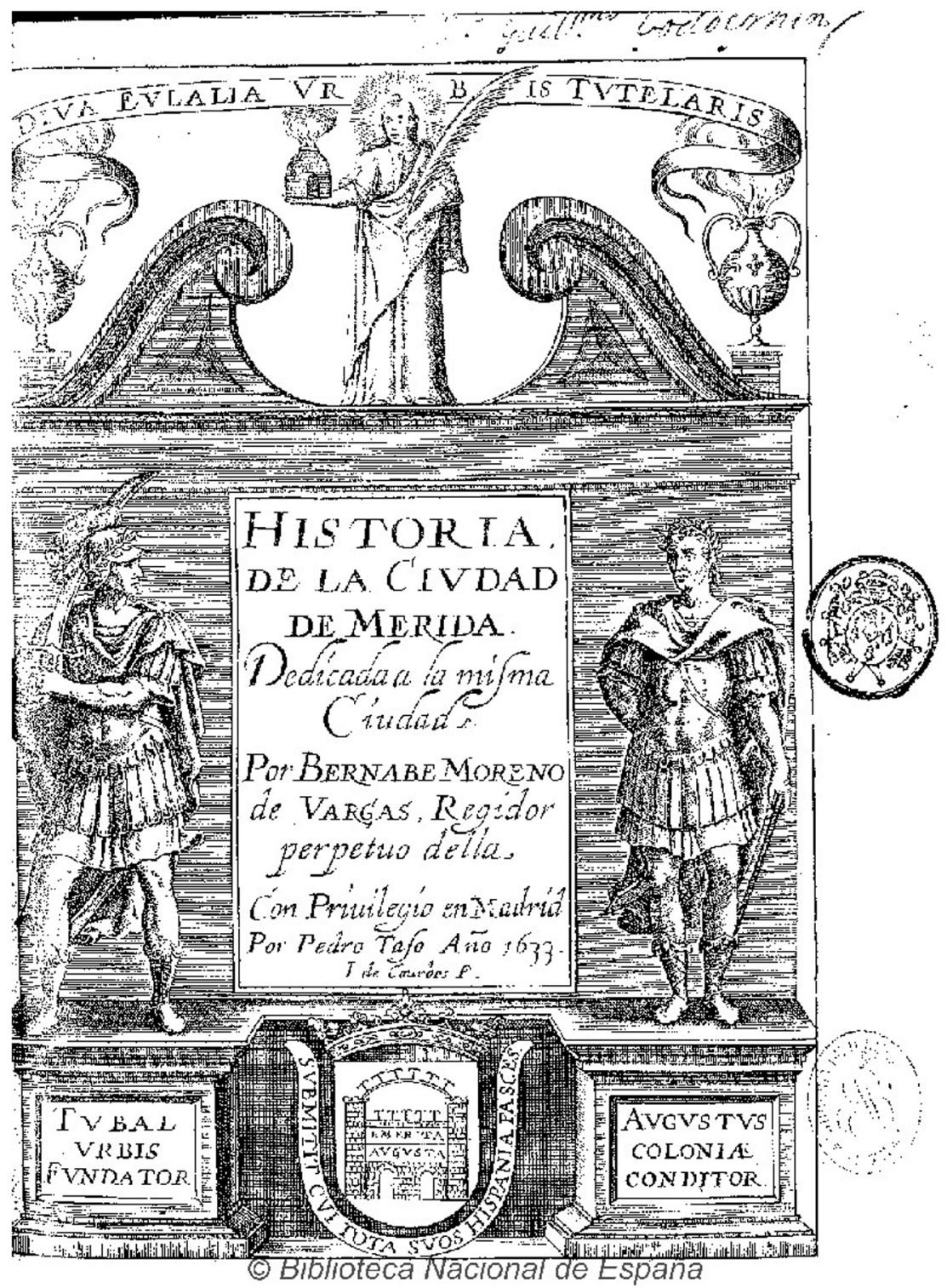

Fig. 8. Portada de la obra de Bernabé Moreno de Vargas, Historia de la ciudad de Mérida de 1633, en la que aparece el nuevo escudo de la ciudad. Ejemplar de la Biblioteca Nacional de España. 
necesaria para reforzar el vínculo con la santa mártir, que en este contexto actuó como un elemento identitario más que definió, prestigió y exaltó la conciencia cívica local.

\section{ELCHE Y EL MANTENIMIENTO DE LA MURALLA}

Los escudos que lucen los tambores de dos cruces de término del siglo XV expuestos en el Museo Arqueológico y de Historia de Elche (fig. 9), la campana fechada en 1572 que da las horas en la torre de la Vela y reloj de Calendura, o las armas ubicadas en el arco norte del interior de la lonja de la torre del Consejo, procedentes al parecer de la casa de la Corte del Justicia (Elche.com., 2014), confirman que el antiguo blasón municipal tenía como imagen principal la representación de la puerta de la ciudad conocida como La Lucentina, amurallada con dos torres, siendo la llamada de La Calahorra la de mayor altura (Hinojosa, 1992, 165-179).

Sin embargo, en 1621 el regidor de la villa, Cristóbal Sanz Agullana, redactó un manuscrito dirigido al justicia y jurados que tituló Recopilación en que se cuenta de las cosas así antiguas como modernas de la ínclita Villa de Elche, sacadas de diversos autores y entendidas personas fidedignas ${ }^{10}$, en cuya portada aparece un nuevo blasón oval de dos cuarteles (fig. 10). Mientras que en el superior se mantuvo la composición medieval descrita sobre un fondo de gules, en el inferior se muestra un ara sobre fondo de sinople con la leyenda SALVTI AVGVSTI en su interior y las siglas C I I A al lado de los cuatro vértices del altar. Asimismo, también destaca la bordadura de plata con la leyenda en sable ILLICE AVGVSTA COLONIA INMVNIS, y al timbre una figura femenina con una palma en su mano derecha identificada por medio de una cartela como ILLICE VICTRIX.

La ceca de Ilici, colonia inmune citada por Plinio (HN3. 19-20) y asentada en el yacimiento arqueológico de La Alcudia de Elche (Tendero, Ronda, 2014, 226-242; Ramos Fernández, Ramos Molina, Peña, Abad, 2014, 243-250; Abad, 2016), puso en circulación emisiones regulares desde la época del segundo triunvirato (post. 42 a.C.) hasta el reinado de Tiberio (Llorens, 1987, 165-82; 1987a; Ripollès, 2004, 197-201), gobierno este en el que bajo la autoridad de los duunviros M Iulius Settal y L Sesti Celer se acuñaron ases y semis (RPC

${ }^{10}$ Nos valemos del manuscrito original conservado en el Archivo Histórico Municipal de Elche con la signatura b 336 que puede consultarse en red en el siguiente enlace: Archivohistorico.elche.es. [online] Recuperado de: http://www.archivohistorico.elche.es/_ebooks/B_336_0_0_0/0001.jpg [Acceso 20 de agosto de 2018]. 


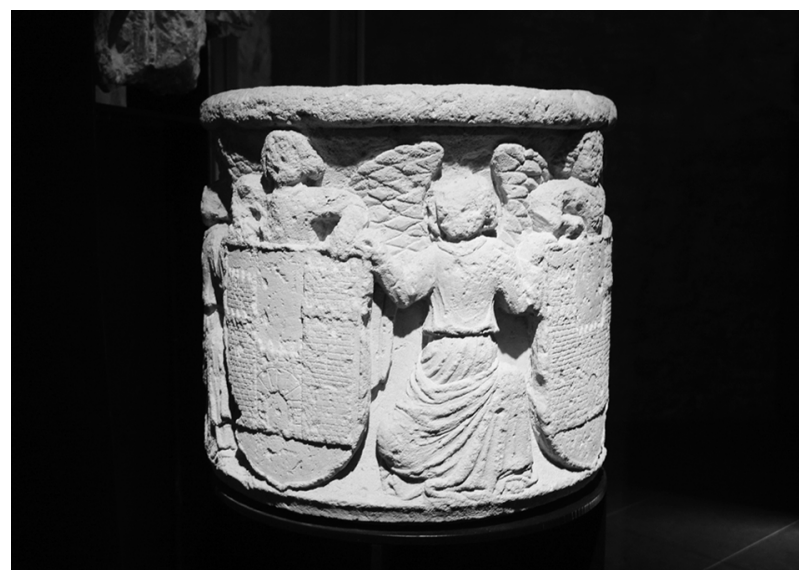

Fig. 9. Escudo medieval de Elche en el tambor de una cruz de término del Museo Arqueológico y de Historia de Elche. (Fotografía: Museo Arqueológico y de Historia de Elche "Alejandro Ramos Folqués" - MAHE).

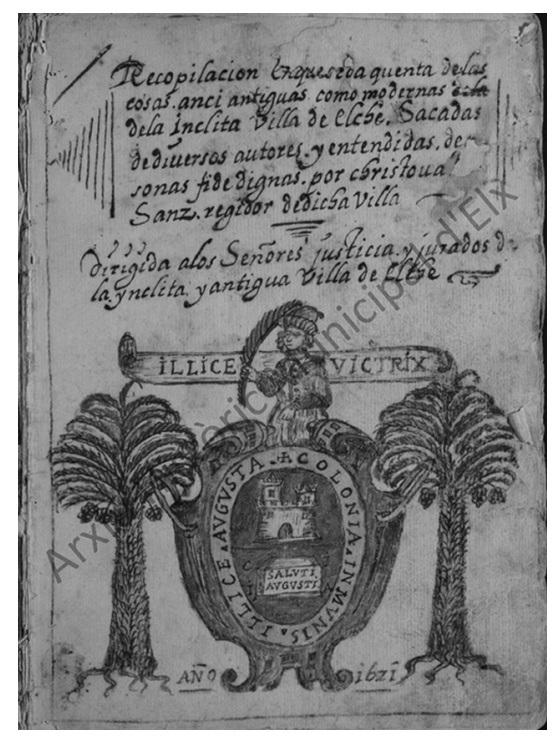

Fig. 10. Portada de la obra de Cristóbal Sanz, Recopilación en que se da quenta de las cosas ancí (sic) antiguas como modernas de la ínclita villa de Elche de 1621, en la que aparece el nuevo escudo concejil. Ejemplar del Archivo Histórico Municipal de Elche. 

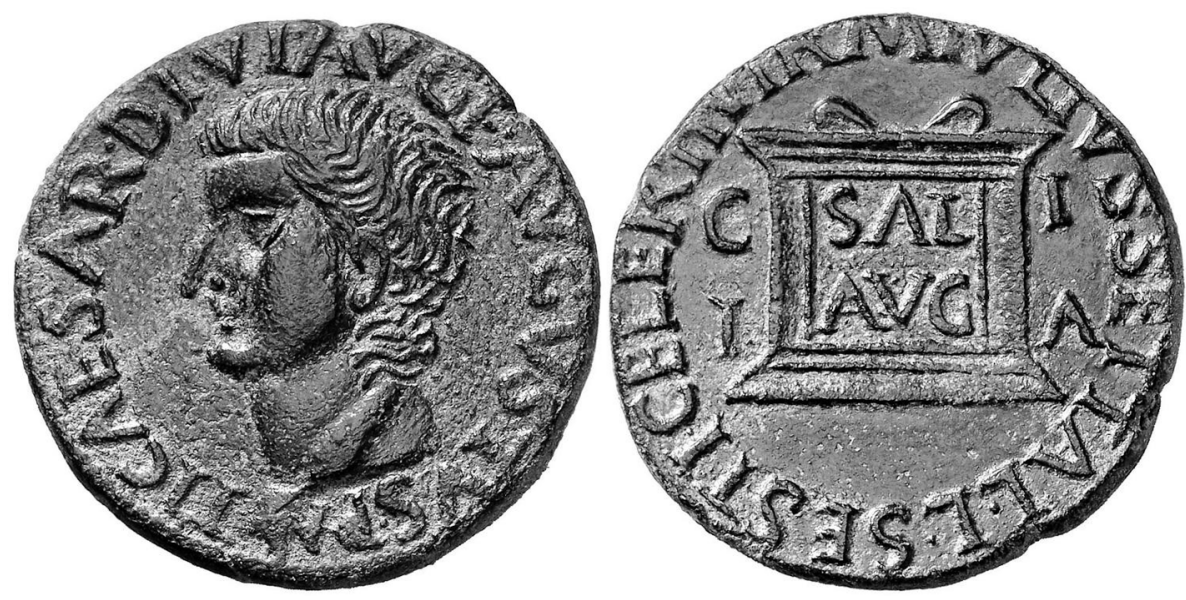

Fig. 11. As acuñado en Ilici (RPC 196) con el altar dedicado a la Salus Augusta como tipo de reverso. 14-37 d.C. (Áureo \& Calicó, auction 311, lot. 82. 31 May 2018. Foto: www.coinarchive.com)

196 y 197) con la tipología del altar en el reverso, la leyenda epigráfica SAL AVG en su interior y las iniciales C I I A flanqueándolo (fig. 11).

Como en el caso de Mérida, la incorporación del altar en el escudo se debió a la competencia y rivalidad con Alicante, que fundamentalmente afectaba a tres cuestiones (Elche.com., 2014): el control y monopolio de las actividades comerciales marítimas desde la Antigüedad (Hinojosa, 1989, 311-324; Márquez, 1999), su identificación con la colonia de $I l i c i^{11}$ y la reivindicación como natural del mártir San Agatángelo, disputa esta a la que también se sumó Orihuela (Alicante) (Castaño, 2001, 57-74; Santos, 2005). Con todo, la adopción del altar no supuso la eliminación del diseño heráldico anterior, sino que se

${ }^{11}$ No debe pasarse por alto que en 1648 Alicante incorporó a su escudo concejil las iniciales I C A I en referencia a la colonia de Ilici, aunque en 1870 Rafael Viravens cambió su orden por el de C I I A argumentando que el autor del primer molde del escudo no tuvo en cuenta que lo estaba fabricando en negativo, con lo que también pretendía justificar el error en la posición de las letras. Sin embargo, en los años cuarenta del pasado siglo, una vez que se tuvo la certeza de que Alicante no era la sucesora de Ilici sino de Lucentum, se decidió sustituir las iniciales por A L L A, que para unos se desarrollan como Alicante $\mathrm{Lu}$ centum / Lucentum Alicante y para otros como Akra Leuka Lucentum Alicante. Para profundizar en estas cuestiones véase: Figueras (1944) y Ortiz (1990). 
optó porque ambos coexistieran, de lo que se colige que las transformaciones identitarias que se dieron en estos contextos sociales, políticos y religiosos descritos no alcanzaron la intensidad necesaria como barrer por completo la conciencia cívica anterior.

\section{CONCLUSIONES}

A lo largo de estas líneas hemos analizado los procesos por los que las ciudades de Huesca, Mérida y Elche modificaron sus escudos de armas medievales en favor de unas nuevas composiciones heráldicas inspiradas en las imágenes más representativas de sus acuñaciones romanas que, convenientemente reinterpretadas, sirvieron de soporte legitimador a determinadas ideologías ciudadanas.

De este modo, el jinete de Huesca, lanza en ristre, «batalló» en defensa de los derechos históricos de la Universidad oscense frente a la de Zaragoza, remitiendo al pasado romano de la ciudad como capital de Sertorio y a este como fundador mítico de la institución universitaria, unos intereses que la fortificación de sus primitivas armas no podía defender. Tampoco la composición emeritense del león cobijado en un arco proclamaba en toda su intensidad el origen de la ciudad como la Colonia Augusta Emerita, capital de Lusitania, cuna de Santa Eulalia y antigua sede metropolitana frente a las disputas que mantenía con Badajoz, pero sí la puerta geminada amurallada de sus emisiones estatales y locales. Por último, Elche fue la única que no renunció por completo a su identidad ciudadana anterior, pues aunque sumó el icono del altar de la Salus Augusta para reivindicarse como la heredera de Ilici y patria de San Agatángelo ante las pretensiones de Alicante, mantuvo la puerta de la muralla flanqueada por las dos torres.

Todos estos cambios, en definitiva, fueron el fruto de las aspiraciones de la élite política y de los procesos de construcción de discursos identitarios que dirigieron y favorecieron al calor de la importancia que los estudios humanistas dieron a las monedas antiguas, a los referentes e iconografía de la tradición romana y al mismo Imperio como modelo para la Monarquía Hispánica. El valor del culto a los santos defendido por el Concilio de Trento y que tanto protagonismo alcanzó en el mundo de la religiosidad barroca, la rivalidad y competencia entre localidades o el florecimiento de obras corográficas promocionadas por los respectivos concejos municipales también fueron agentes protagonistas que, de manera simultánea, y retroalimentándose, crearon y reforzaron una conciencia cívica local que fue necesario comunicar, reflejar y visibilizar a través de la explotación y proyección oficial de la imagen. 


\section{BIBLIOGRAFÍA}

Abreviaturas de catálogos epigráficos y numismáticos

CIL II = HÜBNER, E. (1869; 1892), Corpus Inscriptionum Latinarum, volumen secundum. Inscriptiones Hispaniae Latinae, Berlin e Inscriptionum Hispaniae Latinarum supplementum, Berlin.

RIC I² = SUTHERLAND, C. H. V. (1984): Roman Imperial Coinage. Vol. 1. From 31 $B C$ to $A D$ 69, London, Spink, pp. xxii + 305, 32 pls.

RPC = BURNETT, A., AMANDRY, M., RIPOLLÈS, P. P. (1992): Roman Provincial Coinage. Vol. 1, From the death of Caesar to the death of Vitellius (44 BC-AD 69), London and Paris, British Museum Press and Bibliothèque nationale de France, 2 vols, pp. xvii + 812, plates 193 .

RPC S = BURNETT, A., AMANDRY, M., RIPOLLÈS, P. P. (1998): Roman Provincial Coinage. Supplement I. London and Paris, British Museum Press and Bibliothèque nationale de France, 60 pp. plus 11 pages of plates.

Fuentes documentales

HUESCA (1587): Ordinaciones del regimiento de la muy illustre y antiquissima ciudad de Huesca / impressas por mandado del Concejo y Consejo, siendo officiales los illustres Carlos Augustin de Cisterer Iusticia, Iuan de Felices Prior, Micer Antonio Iuan Mattheo, Pedro Estevan, Iuan de Lasus Iurados en el año 1587. En Huesca: impressas por Iuan Perez de Valdiuielso [4], 125 [14] p.

MONTER DE LA CUEVA, M. (1585): Oscensis vetustissimi Gymnasii, adversus novam Caesaraugustani attentatan erectionem iuridica propugnatio, Oscae: excudebat Ioannes Perez à Valdivieso [8], 40 p.

MORENO DE VARGAS, B. (1622): Discursos de la nobleza de España, en Madrid: por la Viuda de $\mathrm{Al}^{\circ}$ Martin [8], $136 \mathrm{~h}$.

MORENO DE VARGAS, B. (1633): Historia de la ciudad de Mérida, en Madrid: por la viuda de Alonso Martin: por Pedro Taso [12], 336 h. [2] h.

POLDO D'ALBENAS, J. (1560): Discours historial de l'antique et illustre cité de Nismes, en la Gaule Narbonoise Avec les portraitz des plus antiques et insignes bastiments du dit lieu, reduitz à leur vraye mesure et proportion ensemble de l'antique et moderne ville, Lyon, G. Roville, $226 \mathrm{p}$.

SANZ AGULLANA, C. (1621): Recopilación en que se cuenta de las cosas así antiguas como modernas de la ínclita Villa de Elche, sacadas de diversos autores y entendidas personas fidedignas, Elche, 203 p. Ms.

Bibliografía general

ABAD CASAL, L. (Coord.), (2016): L'Alcúdia d'Elx un paseo por la historia y el entorno, Alicante, Universidad de Alicante, $120 \mathrm{p}$.

AGUILERA HERNÁNDEZ, A. (2016): "Nuevas perspectivas numismáticas en torno a la promoción del Municipium Vrbs Victrix Osca”, Hécate, 3, 79-95. 
ALVAR EZQUERRA, A. (2001): “Corografía y exaltación de lo local en la época de Calderón”, en Alcalá-Zamora, J., Belenguer Cebrià, E. (Coords.), Calderón de la Barca y la España del Barroco, vol. 1, Madrid, Centro de Estudios Políticos y Constitucionales, 445-460.

ÁLVAREZ MARTÍNEZ, J. M. (2006): "Los accesos al recinto de la colonia Augusta Emerita: la puerta del Puente”, en Schattner, TH. G., Valdés Fernández, F. (Eds.), Stadttore. Bautyp und Kunstform (Toledo 2003), Maguncia, Iberia Archaeologica 8, 221-251.

ÁLVAREZ SÁENZ DE BURUAGA, J. (1954): "El escudo de Mérida y su origen romano", Revista de Archivos, Bibliotecas y Museos, 60.1, 229-243.

AMELA VALVERDE, L. (2017): "Las emisiones triunvirales de Nemausus", Hécate, 4, 51-59.

ARANDA PÉREZ, F. J. (2001): “Autobiografías ciudadanas: historias, mitomanía y falsificación en el mundo urbano hispánico de la Edad Moderna”, en García Fernández, E. (Coord.), El poder en Europa y América: mitos, tópicos y realidades, Bilbao, Universidad del País Vasco, Servicio de Publicaciones, 141-168.

ARANDA PÉREZ, F. J. (2006): “'Repúblicas ciudadanas'. Un entramado político oligárquico para las ciudades castellanas en los siglos XVI y XVII", Estudis, 32, 7-48.

ARANDA PÉREZ, F. J. (2014): “Un reino de repúblicas: comunidades políticas ciudadano-oligárquicas y su representación en la Castilla Moderna”, en Faya Díaz, M. a Á. (Coord.), Las Ciudades Españolas en la Edad Moderna: Oligarquías Urbanas y Gobierno Municipal (Oviedo, 2012), Oviedo, KRK Ediciones, 23-62.

BALLESTEROS DÍEZ, J. A. (2004): "Mérida, clave en la fundación de la Orden de Santiago", Espacio, tiempo y forma. Serie III. Historia medieval, 17, 53-66.

BARRERA ANTÓN, J. L. de la (1993): "El llamado 'obelisco’ de Santa Eulalia en Mérida y sus piezas romanas”, en Nogales Basarrate, T. (Coord.), Actas de la I Reunión sobre escultura romana en Hispania (Mérida, 1992), Mérida, Ministerio de Cultura, Museo Nacional de Arte Romano de Mérida, 125-140.

BESOMBES, P. A. (2008): “L'ouverture de l'atelier 'imperial' de Nîmes et la première émission d'as au crocodile”, en García-Bellido, M. a P., Mostalac Carrillo, A., Jiménez Díez, A. (Coords), Del "imperium" de Pompeyo a la "auctoritas" de Augusto. Homenaje a Michael Grant (Zaragoza, 2007), Madrid, CSIC / Instituto de Historia, 235-242.

BLÁZQUEZ CERRATO, C. (2013): “Emblema Hispaniae: la percepción histórica de España a través de la Numismática en los textos humanísticos”, en Castro Santamaría, A., García Nistal, J. (Coords.), La impronta humanista (ss. XV-XVIII). Saberes, visiones e interpretaciones, Palermo, Officina di Studi Medievali, 363-376.

BLÁZQUEZ CERRATO, C. (2014): "Los valores del rey: el uso de las antiguas monedas en la configuración de la imagen de Carlos V”, en García Nistal J. (Coord.), Imagen y documento: materiales para conocer y construir una historia cultural, León, El Forastero, D.L. 2014, 15-36.

BLÁZQUEZ CERRATO, C. (2016): “Los 'libros de medallas' renacentistas como referentes sociales y artísticos”, en Actas del XV Congreso Nacional de Numismática (Madrid, 28-30 octubre 2014), Madrid, Museo Arqueológico Nacional, 1217-1230. 
CASTAÑO I GARCÍA, J. (2001): “Sant Agatàngel, sant il·licità?”, La Rella, 14, 57-74. CASTRO MATEOS, A. (2012): La construcción de lo sagrado: Santa Eulalia de Mérida (y su extensión por el levante español), Cáceres, Universidad de Extremadura, 502 p. [online]. Recuperado de: https://core.ac.uk/download/pdf/72043138.pdf [Acceso 20 de agosto de 2018].

CEBRIÁN SÁNCHEZ, M. Á. (2013): La ceca romana de Augusta Emerita, Montpellier, OMNI, $270 \mathrm{p}$.

CERRILLO MARTÍN DE CÁCERES, E. (2009): “La invención de la antigüedad. El caso de Extremadura durante los siglos XVI y XVII", en Gorges, J.-G., D’Encarnação, J., Nogales Basarrate, T., Carvalho, A. (Coords.), Lusitânia romana entre o mito e a realidade, Actas da VI Mesa-Redonda Internacional sobre a Lusitânia Romana (Novembro, 2004), Cascais, Câmara Municipal de Cascais, 25-51.

CORDERO ALVARADO, P. (2005-2006): "Evolución histórica del escudo de armas de la ciudad de Badajoz", Anales de la Real Academia Matritense de Heráldica y Genealogía, 9, 183-228.

CUNNALLY, J. (1999): Images of the Illustrious. The numismatic presence in the Renaissance, Princeton, Princeton University Press, 216 p.

DOMÍNGUEZ ARRANZ, A. (1991): Medallas de la antigüedad. Las acuñaciones ibéricas y romanas de Huesca, Huesca, Ayuntamiento de Huesca, 394 p.

DOMÍNGUEZ ARRANZ, A. (2008): "Nada es más hermoso que conocer: Lastanosa, entre el anticuarismo y la erudición”, Saguntum, 40, 205-218.

DOMÍNGUEZ ARRANZ, A., AGUILERA HERNÁNDEZ, A. (2014): “Del oppidum de Sertorio al municipium de Augusto: la historia reflejada en el espejo de las monedas", Bolskan, 25, 91-109.

DURAND, R. (1962): Les Armoiries de la ville de Nîmes, Nimes, impr. Chastanier frères et Bertrand, $52 \mathrm{p}$.

EGIDO MARTÍNEZ, A. (1984): "Numismática y Literatura: De los Diálogos de A. Agustín al Museo de Lastanosa", en Estudios sobre el Siglo de Oro. Homenaje ofrecido a Francisco Ynduráin, Madrid, Editora Nacional, 211-227.

ELCHE.COM. (2014). Museus - Moneda romana i figura femenina "Illice Victrix" (la iconografia de l'escut d'Elx) - Ajuntament d'Elx. [online]. Recuperado de: http:// www.elche.com/micrositios/museos/info/2217/pieza-del-mes-anterior-mahe-lapieza-del-mes/?set_language=va [Acceso 20 de agosto de 2018].

FIGUERAS PACHECO, F. (1944): El nuevo escudo de la ciudad de Alicante, Valencia, Saitabi / Univ. de Valencia, 222 p.

GARCÉS MANAU, C. (2002): “Quinto Sertorio, fundador de la Universidad de Huesca. El mito sertoriano oscense", Alazet, 14, 243-256.

GARCÉS MANAU, C. (2006): El escudo de Huesca: historia de un símbolo, Huesca, Ayuntamiento de Huesca, $106 \mathrm{p}$.

GODOY ALCÁNTARA, J. (1868): Historia crítica de los falsos cronicones, Madrid, Real Academia de la Historia, 343 p.

GÓMEZ ZORRAQUINO, J. I. (2010): “Los santos patronos y la identidad de las comunidades locales en la España de los siglos XVI y XVII", Revista de Historia Jerónimo Zurita, 85, 39-74. 
HERNÁNDEZ RAMÍREZ, J. (1998): Augusta Emerita. Estructura Urbana, Badajoz, Diputación de Badajoz, Departamento de Publicaciones, 270 p.

HINOJOSA MONTALVO, J. (1989): "El cap del Aljup, puerto medieval de Elche", Mayurqa, 22, 1, 311-324.

HINOJOSA MONTALVO, J. (1992): “La muralla medieval de Elche”, Investigaciones Geográficas, 10, 165-179.

JARQUE MARTÍNEZ, E. (2013): “Los 'paracronistas' aragoneses en los siglos XVI y XVII”, Revista de Historia Jerónimo Zurita, 88, 171-198.

KAGAN, R. L. (1995): "La corografía en la Castilla moderna. Género, historia, nación”, Studia historica. Historia Moderna, 13, 47-60.

LLORENS FORCADA, M. a del M. (1987): "Estimación del número de cuños originales y volumen monetario de la ceca de Ilici”, Lucentum, 6, 165-182.

LLORENS FORCADA, M. ${ }^{\mathrm{a}}$ del M. (1987a): La ceca de Ilici, Valencia, Generalidad Valenciana, $172 \mathrm{p}$.

LÓPEZ FERNÁNDEZ, M. (2009): "Mérida y la Orden de Santiago en las décadas centrales del siglo XIII (1231-1274)", Revista de Estudios Extremeños, 65, 1, 143-174.

MARAVALL CASESNOVES, J. A. (1966): Antiguos y Modernos. Visión de la historia e idea de progreso hasta el Renacimiento, Madrid, Alianza, 628 p.

MARQUES DE FARIA, A. (2001): “Pax Iulia, Felicitas Iulia, Liberalitas Iulia”, Revista Portuguesa de Arqueologia, 4, n. ${ }^{\circ}$ 2, 351-362.

MÁRQUEZ VILLORA, J. C. (1999): El comercio romano en el Portus Ilicitanus. El abastecimiento exterior de productos alimentarios (siglos I a.C. - V d.C.), Alicante, Publicaciones de la Universidad de Alicante, $537 \mathrm{p}$.

MARTÍNEZ LLORENTE, F. (2011): "Del sello al escudo de armas: aproximación a la génesis de la heráldica institucional", en El escudo de Gipúzkoa. Una aproximación a la Heráldica Institucional de los territorios de lengua vasca, San Sebastián, Eusko Ikaskuntza, 151-166.

MENÉNDEZ PIDAL DE NAVASCUÉS, F. (1993): Los emblemas heráldicos. Una interpretación histórica, Madrid, Real Academia de la Historia, 132 p.

MENÉNDEZ PIDAL DE NAVASCUÉS, F. (1999): “Del emblema sigilar a las armerías de las ciudades", en Actes du XXI Congrés International des Sciences Genéalogique et Héraldique à Luxembourg (Luxembourg, 1994), Luxembourg, Association luxembourgeoise de généalogie et d'héraldique, 309-322.

MORALES-POGONOWSKI MARTÍN, J. A. (2001): Escudo de Armas y Enseñas de la Ciudad de Mérida, Badajoz, Diputación de Badajoz, 182 p.

ORTIZ CASTRILLO, F. (1990): El escudo heráldico municipal de Alicante, Alicante, Ayuntamiento de Alicante, $159 \mathrm{p}$.

PUECH, P-F., PUECH, B., PUECH, F. (2014): “The ‘As de Nîmes', a Roman Coin and the Myth of Antony and Cleopatra: Octavian and Agrippa victorious over Antony", OMNI, 8, 58-66.

RAMOS FERNÁNDEZ, R., RAMOS MOLINA, A., PEÑA DOMÍNGUEZ, D., ABAD CASAL, L. (2014): (2014): “Ilici: La fundación universitaria 'La Alcudia' de In- 
vestigación Arqueológica. Génesis y funcionamiento”, en Olcina Doménech, M. H. (Coord.), Ciudades romanas valencias (Valencia, 2013), Valencia, Museo Arqueológico de Alicante - MARQ, 243-250.

RIPOLLÈS ALEGRE, P. P. (2004): "La moneda en Ilici”, en Catálogo de la exposición: Iberia, Hispania, Spania: una mirada desde Ilici, Alicante, Caja de Ahorros del Mediterráneo, 197-206.

SANTOS ALONSO, H. (2005): Historia de San Clemente y San Agatángelo, Elche, Instituto Municipal de Cultura, $64 \mathrm{p}$.

SANZ CAMAÑES, P. (1992): “La ciudad de Huesca ante los sucesos de 1591 y 1592”, Revista de Historia Jerónimo Zurita, 65-66, 67-84.

SANZ CAMAÑES, P. (2000): "Las ciudades al servicio del Rey. La defensa del Pirineo aragonés ante la invasión del Valle de Tena en 1592”, en Martínez Ruiz, E. (Coord.), Actas del Congreso: Madrid, Felipe II y las ciudades de la monarquía (Madrid, 1998), vol. 1, Madrid, Actas Editorial, 143-156.

SAUZET, R. (1998): “L'image de Nîmes antique dans l'historiographie et la mémoire collective locale aux xvii et xviii ${ }^{\mathrm{e}}$ siècles", en Petitfrère, C. (Dir.), Images et imaginaires dans la ville à l'époque moderne, Tours, Presses universitaires FrançoisRabelais, 49-61.

SERRANO MARTÍN, E. (2016): “1542-1618. El período fundacional”, en Lomba Serrano C., Rújula López, P. (Coords.), Historia de la Universidad de Zaragoza, Zaragoza, Prensas Universitarias de Zaragoza, 42-87.

SUSPÈNE, A. (2012): "Monnaies locales et identités: le cas du monnayage colonial du la Nîmes augustéenne", Revue Numismatique, 6e série, t. 168, 23-34.

TENDERO PORRAS, M., RONDA FEMENIA, A. M. (2014): "Ilici: la ciudad romana de Ilici”, en Olcina Doménech, M. H. (Coord.), Ciudades romanas valencias (Valencia, 2013), Valencia, Museo Arqueológico de Alicante - MARQ, 226-242.

VALERO DE BERNABÉ Y MARTÍN DE EUGENIO, L. (2007): Análisis de las características generales de la heráldica gentilicia española y de las singularidades heráldicas existentes entre los diversos territorios históricos hispanos, Madrid, Universidad Complutense de Madrid, 733 p. [online]. Recuperado de: https://eprints. ucm.es/7764/1/T30274.pdf [Acceso 20 de agosto de 2018].

VEYRAC, A. (1998): Le symbolisme de l'as de Nîmes au crocodile, éd. Monique Mergoil, Montagnac, 1998, 73 p.

WULFF ALONSO, F. (2003): Las esencias patrias: historiografía e historia antigua en la construcción de la identidad española (siglos XVI-XX), Barcelona, Crítica, $292 \mathrm{p}$. 